\title{
The Application of Genetic Algorithm in Motion Detection for Data Storage Optimization
}

\author{
John Carlo M. Butil, Ma Lei Frances Magsisi, John Hart Pua, Prince Kevin Se, and Ria Sagum
}

\begin{abstract}
The study focuses on detecting motion and capable of emitting insignificant parts of video from the captured frames from IP Camera and enhancing available data storage. This study embarks a system that is capable of minimizing the video in terms of eliminating frames which can't be used or are any of value to maximize the data storage available. Using the experimental method of research, the researchers evaluated the system based on the result of the experiments with regards to the scope and limitation of the problem and they assessed the accuracy of the system as highly acceptable. Implementing genetic algorithm helps the system to accurately detect motion and therefore optimize the data storage.
\end{abstract}

Index Terms - Genetic algorithm, data storage optimization motion detection, surveillance system.

\section{INTRODUCTION}

Most surveillance systems in place today make use of hard disks to store surveillance images digitally. With hard drive capacity doubling approximately every two years and the cost per unit shrinking by $50 \%$ surveillance storage is less expensive, more efficient and progressively powerful [1]. But there are vast amount of data storage being wasted for CCTV equipment for storing large amount of CCTV captured video which has insignificant frames waiting to be disposed. The study aims to know how huge the amount of data storage can be saved using Genetic Algorithm motion detecting IP camera system that detect motions through a number of Image processing and outputs motion detected frames. The study helps in maximizing data storage while recording videos by removing the appearance of frames with similar images in a sequence. The IP Camera captures the video first then the program loads captured video to be processed. Then, the Image processing and the Application of Genetic Algorithm follows. Lastly, the optimized video is to be outputted. The optimized video will then be analyzed for the amount size lost from the original.

The rest of the paper is organized as follows: In Section II, we discuss the related work. Section III presents a scalable statistical treatment for the study. In Section IV, we present and analyze data that are gain from the course of the study. In Section V, we introduce recommendations for further studies about Data Storage Optimization in Surveillance Systems. Finally, we make some conclusions in Section VI.

Manuscript received January 5, 2014; revised March 3, 2014.

The authors are with Department of Computer Science, College of Computer and Information Sciences, Polytechnic University of the Philippines, Mabini Campus, Sta. Mesa, Manila, Philippines (e-mail: johncarlo.butil@gmail.com, ma.leifrancesmagsisi@yahoo.com.ph, johnhartpua@gmail.com, riasagum@pup.edu.ph).

\section{RELATED WORKS}

\section{A. Genetic Algorithm for Motion Detection}

Genetic algorithm is used for an optimal determination of transforming for every compared object [2]. The system uses the changes in brightness level value to identify the movement. With the use of move analysis method, the system analyze the difference between two image sequence captured in a sequence of digital still images which is time-spatial images.

There is an android code used to detect motion by comparing two images [3]. It comes with an activity that initializes a camera that grabs two images and compares them. The programmer creates a Motion Detection class used to detect motion by comparing RGB values called RGB Motion Detection, a class that detects motion by comparing the luminance values called LumaMotionDetection.java, and using another class called AggregateLumationDetection.java used to detect motion by comparing the luminance value in regions.

Genetic algorithms are used as a tool which lets to put in order a chaotic (random) objects collection [4]. And this algorithm help the system to mark or label object on each frame. And the labeled object is considered as an object in motion by the system.

Genetic algorithms (GAs) are an optimization technique which involves a search from a population of solutions rather than from a single point [5]. The paper entitled "Calibrating a motion detection system by means of a distributed genetic algorithm" shows how a distributed implementation of a GA over a network of workstations can successfully accomplish the parameter optimization task within a motion detection system and achieve excellent performance within a reduced amount of time.

In this study, a real-time intelligent surveillance system capable of analyzing and detecting alarm events was created [6]. Using a gray scale camera to get the input and applying some image processing operations, the desired data were acquired which can use by the system as data by identifying of interest, tracking the aforementioned objects, and analyzing their behavior. A technology for detecting and tracking objects has been presented in the research [6] that is consist of IP Camera and NVR. The proposed algorithm consists of two parts of detecting the moving objects and tracking them. The detecting stage is performed through the extraction of moving objects by RGB BM. The tracking stage is activated when a moving object is detected. The tracking stage uses the geometric information of groups such as the previous position, the variation, the predicted position, and the current position. 


\section{B. Data Storage Maximization}

The surveillance industry continues to transition from analog to digital [1]. This transition is taking place on two fronts - how the images are captured and how they are stored. The way surveillance images are stored has also changed from analog-based recording solutions - like VHS tapes and film - to digital storage on hard drives. As a result, CCTV equipment uses digital storage for storing images. Data storages such as hard drive are getting more feasible using as storage devices for surveillance systems.

\section{SYSTEM ARCHITECTURE}

The system architecture is composed of three major components: (1) Frame Filtration (2) Frame Segmentation (3) Video processing. The input and the output of the system is a video. The system captures a video using an IP camera. On frame filtration, the video captured is then fetch by the system and undergoes to video to frames processing. The video go through a segmentation process which video is being divided into parts. The segmented video will now go to a process of converting video parts and generate RGB frames.

On frame segmentation, the generated frames in RGB are now being manipulated using Genetic Algorithm to check if the frames from the inputted video have significant movement that should be detected by the system. The frames will undergo several processes to detect motion. Genetic Algorithm will generate Population from the frames. From the population, chromosomes will be generated through the division of pixels. Crossover will take place as the chromosomes or genes are compared to the parent genes. The chromosomes that have same genes with the parent will be fetched and mutated to generate frames with motion only. The final component - video processing is the processing of the frames to be stitched and create the output video. Please refer to Fig. 1.

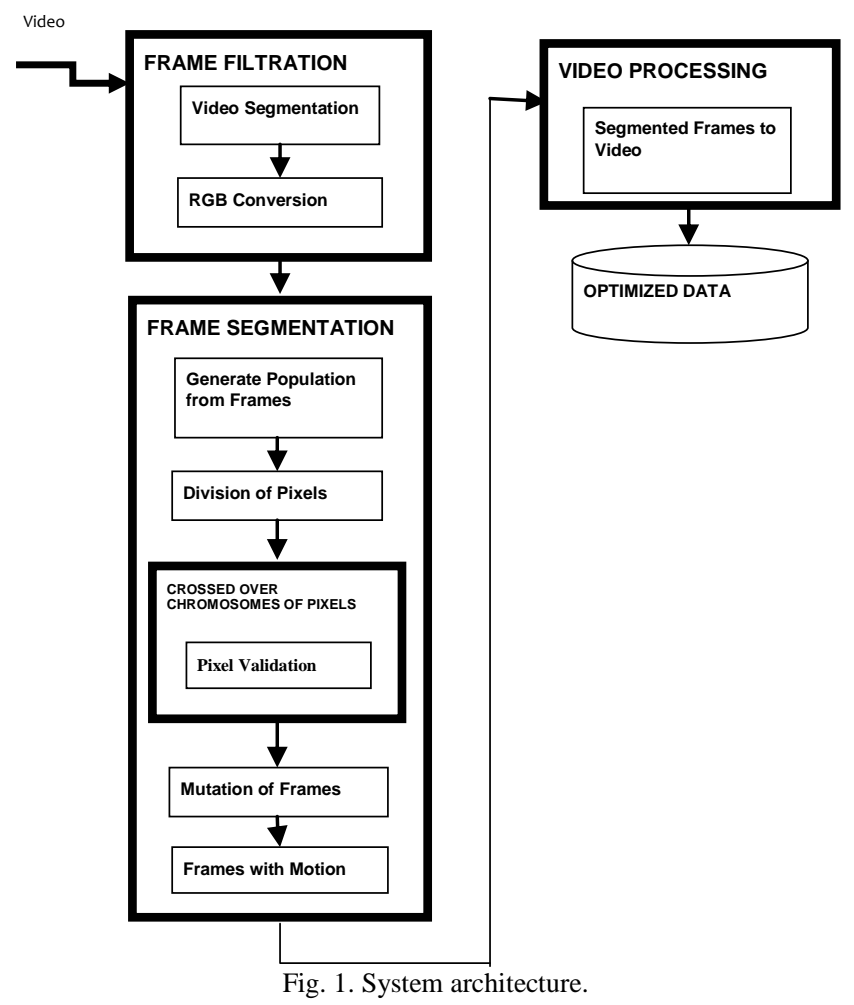

\section{STATISTICAL TREATMENT OF THE STUDY}

The following statistical tool was used in the research study.

- Percent Error

This tool is used to calculate absolute percentage error. It calculates the error percentage ration of the observed value and the true value.

The following is the formula for computing \%error:

$$
\text { \%error }=\left(\left|\frac{y-x}{x}\right|\right) * 100
$$

where $x=$ Total no. frames with motion; $y=$ No. of frames with motion detected.

- Percentage of Accuracy

This tool is used to calculate the percentage of accuracy from the given percent error.

The following is the formula for computing \%accuracy:

$$
\% \text { accuracy }=100-\% \text { error }
$$

- Difference formula

This tool is used to calculate the percentage of the data that is saved using the system.

$\%$ datasave $=\left(\left(x 1+\frac{x 2}{t s}\right) * 100\right)-\left(\left(y 1-\frac{y 2}{t s}\right) * 100\right)$

$x 1=$ size of unprocessed video with motion

$x 2=$ size of unprocessed video without motion

$y 1=$ size of processed video with motion

$y 2=$ size of processed video without motion

$t s=$ total size of data storage

\section{PRESENTATION OF DATA}

The data being presented come from experimenting with the system. With the parameters of the system pertaining to motion detection: Lumens present and distance of an object from the camera. Lumens are defined as 150, 250 and 500lux. Distances are defined as 1, 3 and 5 meters.

In Table I, the average accuracy rate of the system in videos with motion with varying luminance of the environment and constant distance of the object from the camera tested in 150 lux at 1 meter distance is $99.98 \%$. The researcher also tested the system in 250 lux at 1 meter and attained an accuracy rate of $99.76 \%$. The highest luminance of the environment that the researchers tested the system was 500 lux with a distance of 1 meter and an accuracy rate of $94.48 \%$ was attained.

TABLE I: SUMMARY OF FINDINGS IN THE ACCURACY OF MOTION DETECTION IN VIDEOS WITH MOTION WITH RESPECT TO LUMINANCE OF THE ENVIRONMENT

\begin{tabular}{|l|l|l|l|}
\hline & $\begin{array}{l}\text { Accuracy } \\
\text { Rate (\%) in } \\
\text { 150 lux @ 1 } \\
\text { meter }\end{array}$ & $\begin{array}{l}\text { Accuracy } \\
\text { Rate (\%) in } \\
\text { 250 lux @ 1 } \\
\text { meter }\end{array}$ & $\begin{array}{l}\text { Accuracy } \\
\text { Rate (\%) in } \\
\text { 500 lux @ 1 } \\
\text { meter }\end{array}$ \\
\hline Video_1 & 99.99 & 99.94 & 94.44 \\
\hline Video_2 & 99.99 & 99.94 & 95.26 \\
\hline Video_3 & 93.93 & 99.40 & 93.75 \\
\hline AVERAGE & $\mathbf{9 9 . 9 8}$ & $\mathbf{9 9 . 7 6}$ & $\mathbf{9 4 . 4 8}$ \\
\hline
\end{tabular}

In Table II, the average accuracy rate of the system in videos without motion in with varying luminance of the 
environment and constant distance of the object from the camera tested in 150 lux at 1 meter distance is $91.09 \%$. The researcher also tested the system in 250 lux at 1 meter and attained an accuracy rate of $99.46 \%$. The highest luminance of the environment that the researchers tested the system was 500 lux with a distance of 1 meter and an accuracy rate of $97.88 \%$ was attained.

TABLE II: SUMMARY OF FINDINGS IN THE ACCURACY OF MOTION DETECTION IN VIDEOS WITHOUT MOTION WITH RESPECT TO LUMINANCE OF THE ENVIRONMENT

\begin{tabular}{|l|l|l|l|}
\hline VIDEO NAME & $\begin{array}{l}\text { Accuracy } \\
\text { Rate (\%) in } \\
\text { 150 lux @ 1 } \\
\text { meter }\end{array}$ & $\begin{array}{l}\text { Accuracy } \\
\text { Rate (\%) in } \\
\mathbf{2 5 0} \text { lux @ 1 } \\
\text { meter }\end{array}$ & $\begin{array}{l}\text { Accuracy } \\
\text { Rate (\%) in } \\
\text { 500 lux @ 1 } \\
\text { meter }\end{array}$ \\
\hline Video_1 & 94.92 & 99.53 & 98.51 \\
\hline Video_2 & 92.66 & 99.60 & 97.66 \\
\hline Video_3 & 85.69 & 99.26 & 97.46 \\
\hline AVERAGE & $\mathbf{9 1 . 0 9}$ & $\mathbf{9 9 . 4 6}$ & $\mathbf{9 7 . 8 8}$ \\
\hline
\end{tabular}

In Table III, the average accuracy rate of the system in videos with motion with varying distance and constant lux tested in 1 meter distance at 500 lux is $99.94 \%$. The researcher also tested the system in 3 meters distance at 500 lux and attained an accuracy rate of $99.96 \%$. The farthest distance of the object from the camera that the researchers tested the system was 5 meters with a luminance of 500 lux obtained an accuracy rate of $99.94 \%$.

TABLE III: SUMMARY OF FINDINGS IN THE ACCURACY OF MOTION DETECTION IN VIDEOS WITH MOTION WITH RESPECT TO DisTANCE OF THE OBJECT

\begin{tabular}{|l|l|l|l|}
\hline & $\begin{array}{l}\text { Accuracy } \\
\text { Rate (\%) of }\end{array}$ & $\begin{array}{l}\text { Accuracy } \\
\text { Rate (\%) of }\end{array}$ & $\begin{array}{l}\text { Accuracy } \\
\text { Rate (\%) of } \\
\text { VIDEO }\end{array}$ \\
NAME & $\begin{array}{l}\text { 1 meter } \\
\text { distance } \\
\text { @ 500lux }\end{array}$ & $\begin{array}{l}\text { 3 meter } \\
\text { distance } \\
\text { @ 500lux }\end{array}$ & $\begin{array}{l}\text { distance } \\
\text { @ 500lux }\end{array}$ \\
\hline Video_1 & 99.94 & 99.94 & 99.93 \\
\hline Video_2 & 99.95 & 99.96 & 99.95 \\
\hline Video_3 & 99.94 & 99.97 & 99.93 \\
\hline AVERAGE & $\mathbf{9 9 . 9 4}$ & $\mathbf{9 9 . 9 6}$ & $\mathbf{9 9 . 9 4}$ \\
\hline
\end{tabular}

In Table IV, the average accuracy rate of the system in videos without motion with varying distance and constant lux tested in 1 meter distance at 500 lux is $97.88 \%$. The researcher also tested the system in 3 meters distance at 500 lux and attained an accuracy rate of $95.00 \%$. The farthest distance of the object from the camera that the researchers tested the system was 5 meters with a luminance of 500 lux obtained an accuracy rate of $99.86 \%$.

TABLE IV: SUMMARY OF FINDINGS IN THE ACCURACY OF MOTION DETECTION IN VIDEOS WITHOUT MOTION WITH RESPECT TO DISTANCE OF THE OBJECT

\begin{tabular}{|c|c|c|c|}
\hline VIDEO NAME & $\begin{array}{l}\text { Accuracy } \\
\text { Rate }(\%) \text { of } \\
1 \text { meter } \\
\text { distance } \\
\text { @ 500lux }\end{array}$ & $\begin{array}{l}\text { Accuracy } \\
\text { Rate }(\%) \text { of } \\
3 \text { meter } \\
\text { distance } \\
\text { @ 500lux }\end{array}$ & $\begin{array}{l}\text { Accuracy } \\
\text { Rate }(\%) \text { of } \\
5 \text { meter } \\
\text { distance } \\
\text { @ 500lux }\end{array}$ \\
\hline Video_1 & 98.51 & 95.01 & 100 \\
\hline Video_2 & 97.66 & 94.84 & 99.87 \\
\hline Video_3 & 97.46 & 95.14 & 99.72 \\
\hline AVERAGE & 97.88 & 95.00 & 99.86 \\
\hline
\end{tabular}

In Table $\mathrm{V}$ different videos were tested to show the percentage amount difference of the original video to the processed video pertaining to the optimization of the data storage with varying parameters.

TABLE V: SUMMARY OF FINDINGS IN THE OPTIMIZATION OF THE DATA STORAGE WITH THE INPUT VIDEOS

\begin{tabular}{|l|l|l|l|l|l|}
\hline \multirow{3}{*}{ Lux } & \multirow{2}{*}{ Distance } & \multicolumn{3}{|c|}{$\begin{array}{l}\text { Percentage of the Amount } \\
\text { Difference(per trial) }\end{array}$} & Average \\
\hline \multirow{3}{*}{$\begin{array}{l}150 \\
\text { lux }\end{array}$} & 1 meter & 1 & 2.95 & 5.93 & $\mathbf{3 . 2 9}$ \\
\cline { 2 - 6 } & 3 meters & 0.91 & 2.73 & 5.42 & $\mathbf{3 . 0 2}$ \\
\cline { 2 - 6 } & 5 meters & 0.99 & 2.95 & 5.86 & $\mathbf{3 . 2 7}$ \\
\hline \multirow{3}{*}{$\begin{array}{l}250 \\
\text { lux }\end{array}$} & 1 meter & 0.41 & 2.76 & 6.8 & $\mathbf{3 . 3 2}$ \\
\cline { 2 - 6 } & 3 meters & 0.53 & 2.14 & 6.72 & $\mathbf{3 . 1 3}$ \\
\cline { 2 - 6 } & 5 meters & 0.7 & 2.38 & 6.84 & $\mathbf{3 . 3 1}$ \\
\hline \multirow{3}{*}{$\begin{array}{l}500 \\
\operatorname{lux}\end{array}$} & 1 meter & 0.91 & 2.72 & 5.56 & $\mathbf{3 . 0 6}$ \\
\cline { 2 - 6 } & 3 meters & 0.95 & 2.8 & 5.53 & $\mathbf{3 . 0 9}$ \\
\cline { 2 - 6 } & 5 meters & 0.97 & 2.89 & 5.74 & $\mathbf{3 . 2}$ \\
\hline
\end{tabular}

Results tested shows videos with different parameters. The results of the experiment papers show that at 150 lux, the data storage is most optimized at 1 meter and less at 3 meters. At 250 lux, the data storage is most optimized at 1 meter and less at 3 meters. And at 500 lux, the data storage is most optimized at 5 meters and less at 1 meter.

\section{CONCLUSION}

Though precise and careful analysis made by the proponents from the experimentation and implementation of the study named "The Application of Genetic Algorithm optimizing Motion Detection using IP Camera for Data Storage Maximization", the proponents arrived with the following conclusions:

1) Implementing Genetic Algorithm in the system helps to accurately detect motion as the tool gets an accuracy rate of $92.30 \%$ on videos with motion and $87.42 \%$ on videos without motion.

2) Genetic Algorithm provides the optimization of motion detection in the system. It enables the system to filter the inputted video from the source to output a video that only contains the significant parts of the original video.

3) The performance of the system depends on the luminance of the environment. The lesser the luminance, the harder the system can detect motion.

4) Distance of the moving object from the camera is a factor for the system to detect motion. The nearer the moving object the better the system can detect its motion.

5) Data storage of the users of CCTV cameras could be maximized through implementing motion detection in the system and saving significant parts of the recorded videos only.

\section{FUTURE WORKS}

The proponents of this study would like to recommend further development. The recommendations of the researchers are as follows:

1) The future researchers could create a system that is compatible to other operating system such as Ubuntu, Linux, etc.

2) The future researchers can use other algorithms that are effective in detecting motion aside from Genetic Algorithm. 
3) Creating a more user-friendly interface would help the users to operate the system easily.

4) The system created is applicable to be used on commercial establishments for security purposes.

5) Future researchers could add more features that can help increase the credibility of the system in terms of security purposes.

6) The future researchers can develop a system that is suited for a different type of camera.

7) The use of better hardware such as a laptop with a bigger RAM will help the system to perform faster.

Through this study, it is proven that motion detection could help minimize the large consumption of data storage of the conventional security/CCTV cameras. Thus, the recommendations stated above could help future researchers to obtain a better result.

\section{ACKNOWLEDGMENT}

We would like to acknowledge and give thanks to the following persons for their inspirations and contributions which were truly helpful in accomplishing this study.

Our heartfelt thanks to our loving family, for their unceasing moral and financial support. To our friends and classmates, for their ideas which truly helped us, and for extending their support during our hard times.

To the Pua Family, for generously sharing their home to us, for serving great food and for every support they have shown us.

To every dear person that continues to inspire and motivate us. Those who advise us to give our very best to complete this thesis and made us feel extraordinarily happy.

To our Thesis Class Adviser, Prof. Ria A. Sagum, for her unyielding patience and understanding every consultation. For every tip, advices and deadline extensions for us, we thank you.

And finally, we give all thanks to our Almighty God, for giving us the knowledge, wisdom, patience and guidance. $\mathrm{He}$ really makes things possible.

\section{REFERENCES}

[1] Storage technologies for video surveillance. Avigilon - the best evidence. [Online]. Available: http://avigilon.com/white-papers/storage-technologies-for-video-surve illance/, 2013

[2] J. Mamica and T. Walkowiak. "A genetic algorithm for motion detection," Poland: Institute of Engineering Wroclaw University of Technology.

[3] J. Wetherellm. Google project hosting. [Online]. Available. http://code.google.com/p/android-motion-detection/

[4] C. Yang, R. Chen, C. Lee, and S. Lin, "PTZ camera based position tracking in IP surveillance system," in Proc. $3^{\text {rd }}$ International Conference on Sensing Technology, Taiwan, 2008, pp. 142-146.
[5] A. Bevilacqua, "Calibrating a motion detection system by means of a distributed genetic," in Proc. the IEEE International Worshop on Computer Architectures for Machine Perception, 2003, pp. 41-51.

[6] J. Kim, D. Yeom, and Y. Joo, "Fast and robust algorithm of tracking multiple moving objects for intelligent video surveillance system," IEEE Transactions on Consumer Electronics, vol. 57, issue 3, pp. 1165-1170, 2011.

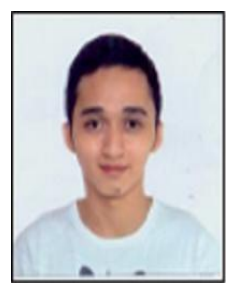

John Carlo M. Butil was born on June 14, 1994 at Manila, Philippines. He is currently taking bachelor of science in computer science in the College of Computer and Information Sciences at Polytechnic University of the Philippines (PUP). He had his internship program at Arcus IT Inc. located at Ortigas Center, Pasig City as a web developer and was exposed to ASP.Net platform.

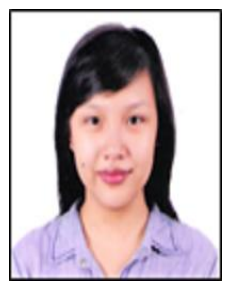

Ma Lei Frances A. Magsisi was born on October 18 , 1993 at Quezon City, Philippines and now living in Antipolo Rizal. Currently taking bachelor of science in computer science at Polytechnic University of the Philippines, Sta. Mesa, Manila. She took her internship program as a web designer at Amberbase Solutions Inc. located at Bagumbayan, Quezon City. She was exposed in managing people and projects as well.

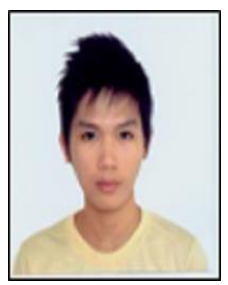

John Hart Pua was born on October 18, 1993 at Manila, Philippines. John Hart is the youngest child in their family. Enrolled at Polytechnic University of the Philippines, taking bachelor of science in computer science at the College of Computer and Information Sciences. He had his internship program as a web developer at Arcus IT Inc. in Ortigas, Pasig and was exposed with ASP.Net and MVC.

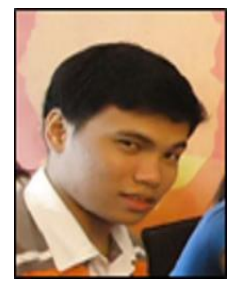

Prince Kevin G. Se was born on April 2, 1994 at Pangasinan, Philippines now currently living in Pasay City. Finishing his college degree of bachelor of science in computer science at Polytechnic University of the Philippines. Took his internship program at Arcus IT Inc. as a web developer and was exposed to ASP.Net. $\mathrm{He}$ is also an expertise in language of $\mathrm{C}$ Sharp (C\#).

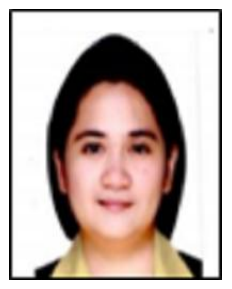

Ria A. Sagum was born in Laguna, Philippines on August 31, 1969. She took up bachelor of computer data processing management from the Polytechnic University of the Philippines and professional education at the Eulogio Amang Rodriguez Institute of Science and Technology. She receive her master's degree in computer science from the De La Salle University in 2012.

She is currently teaching at the Department of Computer Science, College of Computer and Information Sciences, Polytechnic University of the Philippines in Sta. Mesa, Manila and a lecturer at the Information and Computer Studies, Faculty of Engineering, University of Sto. Tomas in Manila. Mrs. Sagum has been a presenter at different conferences, including the 2012 International CConference on e-Commerce, e-Administration, e-Society, e-Education, and e-Technology and National Natural Languange Processing Research Symposium. She is a member of different professional associations including ACMCSTA and an active member of the Computer Society of the Philippines - Natural Language Processing Special Interest Group. 